\title{
Tissue Engineering and Regenerative Medicine
}

\section{Comparison between calcium carbonate and $\beta$-tricalcium phosphate as additives of 3D printed scaffolds with polylactic acid matrix}

\begin{tabular}{|c|c|}
\hline Journal: & Journal of Tissue Engineering and Regenerative Medicine \\
\hline Manuscript ID & TERM-18-0218.R2 \\
\hline Wiley - Manuscript type: & Research Article \\
\hline $\begin{array}{r}\text { Date Submitted by the } \\
\text { Author: }\end{array}$ & 18-Jan-2019 \\
\hline Complete List of Authors: & $\begin{array}{l}\text { Donate, Ricardo; Grupo de Investigación en Fabricación Integrada y } \\
\text { Avanzada. Universidad de Las Palmas de Gran Canaria, Departamento de } \\
\text { Ingeniería Mecánica } \\
\text { Monzón, Mario; Grupo de Investigación en Fabricación Integrada y } \\
\text { Avanzada. Universidad de Las Palmas de Gran Canaria, Departamento de } \\
\text { Ingeniería Mecánica } \\
\text { Ortega, Zaida; Grupo de Investigación en Fabricación Integrada y } \\
\text { Avanzada. Universidad de Las Palmas de Gran Canaria, Departamento de } \\
\text { Ingeniería de Procesos } \\
\text { Wang, Ling; State Key Laboratory for Manufacturing System } \\
\text { Engineering. Xi'an Jiaotong University, School of Mechanical Engineering } \\
\text { Ribeiro, Viviana; 3B's Research Group, I3Bs - Research Institute on } \\
\text { Biomaterials, Biodegradables and Biomimetics, University of Minho; ICVS } \\
\text { 3Bs PT Government Associate Lab; The Discoveries Centre for } \\
\text { Regenerative and Precision Medicine, Headquarters at University of } \\
\text { Minho } \\
\text { Pestana, David; Grupo de Investigación en Fabricación Integrada y } \\
\text { Avanzada. Universidad de Las Palmas de Gran Canaria, Departamento de } \\
\text { Ingeniería Mecánica } \\
\text { Oliveira, Joaquim; 3B's Research Group, I3Bs - Research Institute on } \\
\text { Biomaterials, Biodegradables and Biomimetics, University of Minho; ICVS } \\
\text { 3Bs PT Government Associate Lab; The Discoveries Centre for } \\
\text { Regenerative and Precision Medicine, Headquarters at University of } \\
\text { Minho } \\
\text { Reis, Rui; 3B's Research Group, I3Bs - Research Institute on } \\
\text { Biomaterials, Biodegradables and Biomimetics, University of Minho; ICVS } \\
\text { 3Bs PT Government Associate Lab; The Discoveries Centre for } \\
\text { Regenerative and Precision Medicine, Headquarters at University of } \\
\text { Minho }\end{array}$ \\
\hline Keywords: & $\begin{array}{l}\text { polylactic acid, calcium carbonate, } \beta \text {-tricalcium phosphate, tissue } \\
\text { engineering, bone regeneration, additive manufacturing, porosity, } \\
\text { metabolic activity }\end{array}$ \\
\hline
\end{tabular}




\section{SCHOLARONE ${ }^{\text {m }}$ Manuscripts}




\title{
Comparison between calcium carbonate and $\beta$-tricalcium phosphate as additives of 3D printed scaffolds with polylactic acid matrix
}

\author{
Short running title: Evaluation of polylactic acid-based 3D printed scaffolds for bone regeneration
}

Ricardo Donate ${ }^{1, *}$, Mario Monzón ${ }^{1}$, Zaida Ortega ${ }^{2}$, Ling Wang ${ }^{3}$, Viviana Ribeiro ${ }^{4,5,6}$, David Pestana ${ }^{1}$, Joaquim M. Oliveira ${ }^{4,5,6}$ and Rui L. Reis ${ }^{4,5,6}$.

1 Departamento de Ingeniería Mecánica, Grupo de Investigación en Fabricación Integrada y Avanzada, Universidad de Las Palmas de Gran Canaria, Campus Universitario de Tafira s/n, 35017 Las Palmas, Spain.

2 Departamento de Ingeniería de Procesos, Grupo de Investigación en Fabricación Integrada y Avanzada, Universidad de Las Palmas de Gran Canaria, Campus Universitario de Tafira s/n, 35017 Las Palmas, Spain.

3 State Key Laboratory for Manufacturing System Engineering, School of Mechanical Engineering, Xi'an Jiaotong University, Science and Technology Park of Xi'an Jiaotong University, Yanta District, 710054 Xi'an City, Shaanxi Province, P.R. China.

4 3B's Research Group, I3Bs - Research Institute on Biomaterials, Biodegradables and Biomimetics, University of Minho, Headquarters of the European Institute of Excellence on Tissue Engineering and Regenerative Medicine, AvePark, Parque de Ciência e Tecnologia, Zona Industrial da Gandra, 4805-017 Barco, Guimarães, Portugal.

5 ICVS 3Bs PT Government Associate Lab, Braga, Guimarães, Portugal.

6 The Discoveries Centre for Regenerative and Precision Medicine, Headquarters at University of Minho, AvePark, 4805017 Barco, Guimarães, Portugal.

* Correspondence: ricardo.donate@ulpgc.es; Tel.: +34-928-45-8603

Summary: In this study, polylactic acid-based (PLA) composite scaffolds with calcium carbonate $\left(\mathrm{CaCO}_{3}\right)$ and beta-tricalcium phosphate $(\beta-\mathrm{TCP})$ were obtained by 3D printing. These structures were evaluated as potential 3D structures for bone tissue regeneration. Morphological, mechanical and biological tests were carried out in order to compare the effect of each additive (added in a concentration of $5 \% \mathrm{w} / \mathrm{w}$ ), as well as the combination of both $(2.5 \% \mathrm{w} / \mathrm{w}$ of each one), on the PLA matrix. The scaffolds manufactured had a mean pore size between $400-425 \mu \mathrm{m}$ and a porosity value in the range of 50-60\%. According to the results, both additives promoted an increase of the porosity, hydrophilicity and surface roughness of the scaffolds, leading to a significant improvement of the metabolic activity of human osteoblastic osteosarcoma SaOS-2 cells. The best results in terms of cell attachment after 7 days were obtained for the samples containing $\mathrm{CaCO}_{3}$ and $\beta$-TCP particles due to the synergistic effect of both additives, which results in an increase in osteoconductivity and in a microporosity that favours cell adhesion. These scaffolds (PLA:CaCO $3: \beta-\mathrm{TCP}$ 95:2.5:2.5) have suitable properties to be further evaluated for bone tissue engineering applications.

Keywords: polylactic acid, calcium carbonate, $\beta$-tricalcium phosphate, tissue engineering, bone regeneration, additive manufacturing, porosity, metabolic activity

\section{Introduction}

The use of additive manufacturing techniques has a major interest for the production of parts for the biomedical sector, especially scaffolds (Chia \& Wu, 2015; Li, Li, Lu, Gao, \& Zhou, 2015), which are threedimensional structures used in tissue engineering to guide and promote adhesion, proliferation and migration of cells during the process of tissue regeneration (Gregor et al., 2017; Sachlos, Czernuszka, Gogolewski, \& Dalby, 2003). Currently, the preferred materials for this application are those that are biodegradable and bioresorbable, so the initial foreign material and the bulk degradation by-products are eliminated through natural pathways with no residual side effects (Hutmacher, 2000).

Apart from its bioresorbability, scaffolds should be easily manufactured in different shapes and sizes (Hutmacher, 2000; Sachlos et al., 2003). This requirement could be fulfilled by the method of additive manufacturing, under the category of "material extrusion" (ISO/ASTM 52900:2015), commonly known as fused deposition modeling (FDM). In this process, a continuous filament of material is fed through a moving, heated printer extruder head. FDM has been used for the manufacture of scaffolds with synthetic 
biomaterials such as polycaprolactone (PCL) (Zein, Hutmacher, Tan, \& Teoh, 2002), even reaching the commercial introduction of the technique. Another of the most used biomaterials in FDM is polylactic acid (Esposito Corcione et al., 2017; Gregor et al., 2017; Patrício et al., 2014), being this, like PCL, a biocompatible and biodegradable thermoplastic polymer with low melting temperature (Esposito Corcione et al., 2017). PLA has a lower level of hydrophobicity compared to PCL, which makes it more easily reabsorbable by the organism (Sabino et al., 2013). Disadvantages in the use of PLA for scaffolds manufacturing include the low osteoconductivity of this biomaterial, the deficient cellular adhesion on its surface and, especially, the occurrence of inflammatory reactions as a consequence of the release of acidic species during degradation (Abert, Amella, Weigelt, \& Fischer, 2016). Therefore, for tissue engineering applications, the use of PLA is limited to its use as a composite material in combination with natural or ceramic biomaterials that can counteract the aforementioned deficiencies.

In the present work, calcium carbonate $\left(\mathrm{CaCO}_{3}\right)$ and $\beta$-tricalcium phosphate $\left(\mathrm{Ca}_{3}\left(\mathrm{PO}_{4}\right)_{2}, \beta\right.$-TCP) were evaluated as additives of PLA-based scaffold manufactured by FDM for bone tissue regeneration. $\beta$-TCP is a biodegradable high temperature phase of calcium phosphate that has been used as bone substitute due to its osteoconductivity and bone replacement capability (Canadas, Pina, Marques, Oliveira, \& Reis, 2015). In comparison with hydroxyapatite $\left(\mathrm{Ca}_{5}\left(\mathrm{PO}_{4}\right)_{3} \mathrm{OH}\right)$, another calcium phosphate extensively used as bone scaffolds-filling material, $\beta$-TCP is completely reabsorbed by the organism, while hydroxyapatite has a slow resorption rate and may be integrated into the regenerated bone tissue (Canadas et al., 2015; Takahashi, Yamamoto, \& Tabata, 2005). To counteract the acidic reaction products that could arise from the polymeric degradation, the addition of a buffering agent is a strategy that has been applied in previous studies (Abert et al., 2016; Schiller et al., 2004). As calcium carbonate buffers in the range of the physiological $\mathrm{pH}$ value of around 7.4 (Ara, Watanabe, \& Imai, 2002; Schiller \& Epple, 2003), it is a material of great interest to be added in PLA-based scaffolds.

Although many works can be found in the literature where the use of PLA/ $\beta$-TCP composite scaffolds is investigated (Lou, Wang, Song, Gu, \& Yang, 2014; Rakovsky, Gotman, Rabkin, \& Gutmanas, 2014; Schiller et al., 2004), not a large number of them propose additive manufacturing techniques to obtain the 3D structures (Drummer, Cifuentes-Cuéllar, \& Rietzel, 2012; Esposito Corcione et al., 2017), and no references have been found about the simultaneous addition of $\mathrm{CaCO}_{3}$ and $\beta$-TCP in 3D printed PLA-based scaffolds. For that reason, in this study composite scaffolds containing one of the additives or both of them in combination with the PLA matrix were compared to pure PLA structures. Morphological, mechanical, and biological characterization of the scaffolds were carried out. In addition, the filaments produced to feed the printer were analysed by thermogravimetric and calorimetric analysis and Fourier transform infrared spectroscopy. Water contact angle measurements of the combination of materials proposed were also performed in order to assess the modification of the surface hydrophilicity when additives are used.

\section{Materials and Methods}

\subsection{Materials}

PLAL130 (melt flow index of $16 \mathrm{~g} / 10 \mathrm{~min}$, molecular weight of approximately 100,000 g/mol) was kindly supplied by Corbion Purac in the form of pellets. Glass transition temperature is in the range of 55 to $60{ }^{\circ} \mathrm{C}$ and the melting temperature is $175{ }^{\circ} \mathrm{C}$ according to specifications. Commercial grade calcium carbonate $0179-500 \mathrm{G}$ with a maximum particle size of $30 \mu \mathrm{m}$ was purchased from VWR, while $\beta$-tricalcium phosphate $(\beta-\mathrm{TCP})$ was kindly provided by the 3B's Research Group of Universidade do Minho (UMINHO) with a mean particle size of $45 \mu \mathrm{m}$.

\subsection{Material Compounding and Preparation of Filaments}

PLA pellets were milled at 12,000 rpm in an Ultra Centrifugal Mill ZM 200 (Retsch) to a maximum particle size of $500 \mu \mathrm{m}$. This powder was then mixed with the amount of powder of $\mathrm{CaCO}_{3}$ and $\beta$-TCP needed to obtain the following mixtures (wt:wt): PLA:CaCO $\mathrm{CO}_{3}$ 95:5, PLA: $\beta-\mathrm{TCP}$ 95:5 and PLA:CaCO $3: \beta-\mathrm{TCP}$ 95:2.5:2.5. After homogenization, each combination of materials was fed into a lab prototype extruder to obtain the continuous filaments needed to print the scaffolds by FDM. This extruder consists of an $8 \mathrm{~mm}$ 
screw, a cylinder with an L/D ratio of 10 and a $1.6 \mathrm{~mm}$ diameter nozzle tip. Due to the swelling effect, a diameter for the extruded filaments greater than the nozzle tip diameter was obtained. The extrusion was carried out at $245^{\circ} \mathrm{C}$, at a rotating speed of $7 \mathrm{rpm}$ and with a final air-cooling stage. Filaments of pure PLA were obtained following the same procedure.

\subsection{Scaffolds Fabrication}

The filaments obtained were used to print the parts needed for the different tests described in this report with a BQ Hephestos $23 \mathrm{D}$ printer. Structures with a rectangular $0 / 90^{\circ}$ pattern were printed to carry out the mechanical, morphological and biological characterization of the composite scaffolds. The designed pattern provides square shaped pores in an interconnected network, resulting in scaffolds with a theoretical porosity of $50 \%$ and pore sizes in the range of 350-450 $\mu \mathrm{m}$. All samples were printed using a nozzle diameter of $0.4 \mathrm{~mm}$, a layer height equal to $0.3 \mathrm{~mm}$, a speed of extrusion of $40 \mathrm{~mm} / \mathrm{s}$ and with the temperature of the liquefier set at $225^{\circ} \mathrm{C}$ and room temperature at $23 \pm 1{ }^{\circ} \mathrm{C}$.

In order to estimate the reproducibility of the 3D printer, which could be affected by internal factors such as variation of liquefier temperature, feed rate or cooling process on bed, 25 samples with the same geometry and porosity than the scaffolds of this research were tested using the working parameters described above. These scaffolds were printed using a commercial filament of PLA for 3D printing (1.75 mm, BQ), with high level of uniformity in diameter. The compression test resulted to be about $4 \%$ of variation factor (typical deviation divided by average value) in terms of Young modulus and yield strength. The reproducibility study provided a valuable reference for analysing the influence of other factors in the variation factor of the developed scaffolds (poor uniformity of filaments produced, poor uniformity of distribution of the additives, etc.).

\subsection{Morphological Characterization}

The surface morphology of scaffolds printed by FDM with nominal dimensions of $9.8 \mathrm{~mm}$ in diameter and $7 \mathrm{~mm}$ in height was evaluated by microscopic observation (Olympus BX51 optical microscope), scanning electron microscopy (SEM; Hitachi TM 3030 at an acceleration voltage of $15 \mathrm{kV}$ ) and microcomputed tomography (micro-CT; Y. Cheetah, YXLON Ltd.). Prior to SEM observation, the samples were sputtered with Pd/Au for 2 minutes at $18 \mathrm{~mA}$ in a Polaron SC7620 sputter.

A method broadly used in the literature (Domingos et al., 2013; Yang, Kim, \& Kim, 2017) to estimate the porosity of 3D printed scaffolds was applied using the following equation:

$$
\% \text { porosity }=100 \cdot\left(1-Q_{a p} / Q_{b u l k}\right),
$$

Where $Q_{a p}$ is the apparent density of the structure and Qbulk is the density of the bulk material. The density of the bulk material was determined by measuring the dimensions of short filaments of material with a cantilever $( \pm 0.01 \mathrm{~mm})$ and their mass $(n=8)$. The apparent density was measured following a similar protocol for 3D printed scaffolds of each combination of materials studied.

As the printing pattern was $0 / 90^{\circ}$, the pore size was evaluated as the distance between filaments. These measures were done using the software of the Olympus BX51 optical microscope.

\subsection{Thermogravimetric and Calorimetric Analysis}

Pure PLA filaments and hybrid PLA:CaCO 3 95:5, PLA: $\beta$-TCP 95:5, PLA:CaCO $: \beta-$ TCP 90:2.5:2.5 filaments obtained after the FDM process were subjected to thermogravimetric analysis (TGA) in a TGA/DSC 1 Mettler Toledo device. Pure PLA powder were also analysed using the same procedure. A cycle of heating up to $385^{\circ} \mathrm{C}$ at a heating rate of $10{ }^{\circ} \mathrm{C} / \mathrm{min}$ with a nitrogen flow of $10 \mathrm{~mL} / \mathrm{min}$ was followed in each case, using aluminium crucibles. During the TGA testing, it was possible to obtain the calorimetric data using the same thermal cycle. The melting temperature and the melting enthalpy of each type of sample were calculated using these data. The values of the melting enthalpy were used to calculate the crystallinity of the samples by applying the following equation (Esposito Corcione et al., 2017):

$$
\% \mathrm{X}_{\mathrm{c}}=100 \cdot\left[\Delta \mathrm{H}_{\mathrm{f}} /\left(\Delta \mathrm{H}_{\mathrm{f}}^{\circ} \cdot \mathrm{W}_{\mathrm{PLA}}\right)\right],
$$


where $\mathrm{X}_{\mathrm{c}}$ is the degree of crystallinity, $\Delta \mathrm{H}_{\mathrm{f}}$ is the enthalpy of fusion of the sample, $\Delta \mathrm{H}_{\mathrm{f}}{ }^{\circ}$ corresponds to the heat of fusion of $100 \%$ crystalline PLA, and $W_{\text {PLA }}$ is the net weight fraction of the PLA in the sample tested. The value of $\Delta \mathrm{H}_{\mathrm{f}}{ }^{\circ}$ used in this study was $93.6 \mathrm{~J} / \mathrm{g}$ (Garlotta, 2001).

\subsection{Fourier Transform Infrared Spectroscopy (FTIR)}

Filaments obtained by extrusion were characterized by FTIR. Fourier transform infrared spectra were obtained using a Perkin Elmer IR Spectrum Two in the attenuated total reflectance (ATR) mode. The range of study covers wavelengths from 4000 to $450 \mathrm{~cm}^{-1}$ at a resolution of $8 \mathrm{~cm}^{-1}$. Five measurements were carried out for each group of samples, using twelve scans per measurement to obtain the average spectra.

\subsection{Water Contact Angle Measurement (WCA)}

For this test, non-porous specimens were fabricated. PLA in powder form (obtained as described in Section 2.2) was mixed with the amount of powder of $\mathrm{CaCO}_{3}$ and $\beta-\mathrm{TCP}$ needed to obtain the following mixtures (wt:wt): PLA:CaCO 3 95:5, PLA: $\beta$-TCP 95:5, PLA:CaCO ${ }_{3}: \beta-T C P$ 90:2.5:2.5. After homogenization, these mixtures were subjected to compression moulding in a Collin P $200 \mathrm{P} / \mathrm{M}$ press. The cycle used consisted of a first step of heating at $20{ }^{\circ} \mathrm{C} / \mathrm{min}$ up to $190^{\circ} \mathrm{C}$, a second step of constant temperature and a pressure of 10 bar applied for 90 seconds, and finally a cooling step until room temperature at $20{ }^{\circ} \mathrm{C} / \mathrm{min}$. Pure PLA samples were obtained following the same procedure. Five samples per group were manufactured.

The WCA was determined at room temperature using an optical contact angle measuring device (JC2000D2, Shanghai Zhongchen Digital Technology Apparatus Co., Ltd.) equipped with StreamPix software, by measuring the static contact angle of $2 \mu \mathrm{L}$ distilled water droplets onto the surface of the samples. Reported contact angles are the average of 25 measurements per group (five measurements per sample). The test was carried out both on dry and pre-wetted samples, in order to confirm if the previous hydration of the samples has an effect on their wettability, as other authors have described when working with other polymers (Alemán-Domínguez, Ortega, et al., 2018; Conejero-García et al., 2017; Vallés-Lluch, Gallego Ferrer, \& Monleón Pradas, 2010). After immersion in water for $24 \mathrm{~h}$ to ensure that the water content of the samples reach the equilibrium, the surface of the pre-wetted samples was gently dried with laboratory paper and the WCA was analysed immediately.

\subsection{Mechanical Characterization}

Compression and flexural tests were performed to evaluate the effect of the introduction of the additives in the PLA matrix. The samples were tested on an MTS (SANS CMT4304, MTS Systems Co. Ltd.) universal testing machine in displacement control mode at a crosshead speed of $1 \mathrm{~mm} / \mathrm{min}$.

Regarding the compression test, 3D printed porous scaffolds were tested. The samples were $9.8 \mathrm{~mm}$ in diameter and $7 \mathrm{~mm}$ in height. Five replicas of each combination of materials were tested: PLA, PLA:CaCO 95:5, PLA: $\beta$-TCP 95:5, PLA: $\mathrm{CaCO}_{3}: \beta$-TCP 90:2.5:2.5. The compressive modulus was calculated from the initial steepest straight-line portion of the load-strain curve according to ASTM D695-15. Besides, the offset compressive yield strength was evaluated as the stress at which the stress-strain curve departs from linearity by a $0.2 \%$ of deformation.

For the flexural properties, the 3 points bending test was carried out. Two types of samples were tested separately: 3D printed scaffolds with rectangular shape and dimensions of $25 \times 12.7 \times 3.2 \mathrm{~mm}$ and non-porous samples obtained by compression moulding (as described in Section 2.7) with dimensions of 80x10x1 mm. In both cases, five replicas of samples of each combination of materials were used to obtain the flexural modulus and the maximum flexural stress. The parameters were calculated according to the procedures explained in the standard ASTM D790-15.

\subsection{Metabolic activity of SaOS-2 cells}

A human osteoblastic osteosarcoma cell line (SaOS-2) was used to assess cell behaviour in the presence of the four groups of materials tested: PLA, PLA:CaCO ${ }_{3}$ 95:5, PLA: $\beta$-TCP 95:5 and PLA:CaCO $: \beta-T C P$ 
90:2.5:2.5. Four replicas of 3D printed porous scaffolds of each group, with dimensions of $9.8 \mathrm{~mm}$ in diameter and $7 \mathrm{~mm}$ in height, were tested. Before cell seeding, all samples were hydrated in Dulbecco's Modified Eagle's Medium - low glucose (DMEM - low glucose; Sigma Aldrich, Missouri, EUA) supplemented with $1 \%$ antibiotic-antimycotic solution (Gibco, Life Technologies, Carlsbad, CA, USA), overnight in a $\mathrm{CO}_{2}$ incubator. In the following day, the hydrated scaffolds were transferred to 24-well suspension cell culture plates. Cells were grown as monolayer cultures in standard basal medium consisting of DMEM - low glucose, supplemented with 10\% fetal bovine serum (FBS; Life Technologies, California, USA) and 1\% antibiotic-antimycotic solution. At confluence, cells were detached from the culture flasks using TrypLE Express enzyme with phenol red (Gibco, Life Technologies, Carlsbad, CA, USA), and seeded in a $50 \mu \mathrm{L}$ cell suspension into the scaffolds, at a density of 80,000 cells/scaffold. The constructs were kept in the $\mathrm{CO}_{2}$ incubator for 3 hours and then completed with $2 \mathrm{~mL}$ of culture medium. Samples were harvested after culturing for 1, 3 and 7 days and the culture medium was changed every 2-3 days.

Alamar blue assay was performed to assess the metabolic activity of cells, following the manufacturer's instructions. After each time-point, the constructs were transferred to a new 24-well suspension cell culture plate and a solution of $10 \%(\mathrm{v} / \mathrm{v})$ AlamarBlue ${ }^{\circledR}($ BioRad, Hercules, CA, USA), prepared in standard basal culture medium, was transferred to the culture plates in $1000 \mu \mathrm{L} / \mathrm{scaffold}$. After 3 hours of reaction with cells at $37^{\circ} \mathrm{C}$ in the $\mathrm{CO}_{2}$ incubator, $100 \mu \mathrm{L}$ of Alamar blue solution were taken from each well and placed in a 96well white opaque plate (Corning-Costar Corporation, Acton, MA, USA) in triplicate. The fluorescence was measured in a microplate reader (Synergy HT, BioTek, Instruments, USA) at an excitation wavelength of $530 / 25 \mathrm{~nm}$ and at an emission wavelength of 590/35 nm. Scaffolds without cells were used as control.

After 7 days of culture, the cell-seeded scaffolds were washed with phosphate buffered saline (PBS; Sigma Aldrich, Missouri, EUA) solution and fixed with 2.5\% glutaraldehyde (Sigma Aldrich, Missouri, EUA) solution in PBS for 1 hour at $4{ }^{\circ} \mathrm{C}$. After rising with PBS, samples were dehydrated using a series of ethanol solutions $(30 \%, 50 \%, 70 \%, 90 \%$ and $100 \% \mathrm{v} / \mathrm{v})$ and treated with hexamethylidisilazane (HMDS; Electron Microscopy Sciences, USA). Samples were cut longitudinally to address cell morphology in the scaffold's interior. Samples were sputter coated with gold (Fisons Instruments, Sputter Coater SC502, UK) prior to SEM analysis (Leica Cambridge S360).

\subsection{Statistical Analysis}

Statistical analysis was performed using GraphPad Prism 5.0 software (GraphPad Software, La Jolla, CA, USA) and MATLAB software (MATLAB and Statistics Toolbox Release 2017a, The MathWorks, Inc., Natick, USA). The data obtained during this study were analysed by the Wilcoxon two-sided rank sum test, except for the analysis of the metabolic activity test data. In the latter case, a Kruskal-Wallis test followed by Dunn's post-test were used. The significance level was set to ${ }^{*} p<0.05,{ }^{* *} p<0.01$ and ${ }^{* * *} p<0.001$ for statistically significant, highly statistically significant and very highly statistically significant differences, respectively. All the figures show the mean values of each group and their standard deviations are represented with error bars.

\section{Results}

\subsection{Morphological Characterization}

\subsubsection{Surface Morphology}

As observed in the SEM images shown in Figure 1, while filaments of pure PLA scaffolds showed a smooth surface and steady filaments morphology, filaments of scaffolds composed of PLA mixed with additives exhibited a greater roughness and less constant diameter. On the other hand, according to Figures 1 (e) and (f), a good dispersion of $\mathrm{CaCO}_{3}$ and $\beta$-TCP in the PLA matrix has been achieved. However, agglomerates of the additive particles are also observed in these images, being formed maybe because of the lack of interaction with the matrix or due to a limited mixing performance of the extruder used to manufacture the filaments for 3D printing. In any case, it is highly probable that the presence of these agglomerates is the cause of the final morphology presented by the filaments of the 3D printed scaffolds. 
The surface morphology analysis is completed with the micro-CT images of the scaffolds (Figure 2), where the designed rectangular $0 / 90^{\circ}$ pattern and the $3 \mathrm{D}$ structure reconstruction can be seen in detail. Micro-CT images confirmed that the additives are evenly distributed in the PLA matrix, but also the presence of agglomerates and defects in the filaments. The increase in microporosity of the composite scaffolds is especially evident in the micro-CT scans of the PLA:CaCO $3: \beta-T C P$ 95:2.5:2.5 scaffold.

\subsubsection{Porosity and Pore Size}

The bulk density of PLA L130, used in this work as the matrix of composite 3D printed scaffolds, is 1.20 $\pm 0.03 \mathrm{~g} / \mathrm{cm}^{3}$ according to the results shown in Table 1 (and 1.24 according to the datasheet of the product). The bulk density of the material increased with the addition of $\mathrm{CaCO}_{3}, \beta-\mathrm{TCP}$ and the combination of the two of them. However, the apparent density of the scaffolds remained unchanged for all the groups of samples. As a result, the porosity values were slightly higher in the composite scaffolds, with a statistically significant increment in the case of PLA:CaCO 3 95:5 and PLA: $\beta$-TCP 95:5 samples (Table 1). This result was expected taking into account the conclusions drawn from the SEM and micro-CT images. The average pore size was in the range of $400-425 \mu \mathrm{m}$ for all the groups of scaffolds evaluated (Table 1). There is no statistically significant increase of the distance between filaments (identified herein as pore size) for the composite scaffolds compared to the pure PLA scaffolds.

\subsection{Thermogravimetric and Calorimetric Analysis}

The thermogravimetric analysis allowed obtaining the temperature at which the degradation process of the composite materials starts (left limit temperature in Table 2) and to compare these values to pure PLA. This information was also useful to establish the maximum operation temperature to be used when processing these materials by extrusion and 3D printing. As shown in Table 2, degradation starts at $310{ }^{\circ} \mathrm{C}$ for PLA when it is in powder form or as a 3Dprinted filament. On the other hand, the temperature at which the degradation process start decreases when $\mathrm{CaCO}_{3}, \beta-\mathrm{TCP}$ or both were added to the PLA matrix (from 310 ${ }^{\circ} \mathrm{C}$ to $270-280^{\circ} \mathrm{C}$ ). In spite of this decrease, the degradation temperature is still higher than the melting temperature of all the studied combinations of materials $\left(173-174{ }^{\circ} \mathrm{C}\right)$, and there is a wide safe temperature window to process the proposed combinations of materials by thermal techniques.

The results regarding the degree of crystallinity of the matrix for 3D printed filaments indicate that the use of the additives increases the value of this property (from $31.4 \%$ for pure PLA samples up to $49.8 \%$ in the case of PLA:CaCO $3: \beta-T C P$ 95:2.5:2.5 samples).

\subsection{Fourier Transform Infrared Spectroscopy (FTIR)}

The FTIR spectra have been used to evaluate the interaction between the components in the composite materials, as well as to assess possible changes in the degree of crystallinity of the extruded filaments as complementary information to the calorimetric data (Table 2). No displacement or modification of the peaks, that could confirm an intermolecular interaction between the materials blended, is observed in the FTIR spectra showed in Figure 3. This lack of interaction could be responsible for the agglomeration of the $\mathrm{CaCO}_{3}$ and $\beta$-TCP particles.

Regarding the crystallinity study of the samples derived from FTIR results, and according to literature (Kister, Cassanas, \& Vert, 1998), the regions of interest in the FTIR spectrum because of their high sensitivity to crystallinity changes are: the carbonyl $(\mathrm{C}=\mathrm{O})$ stretching region at $1790-1730 \mathrm{~cm}^{-1}$, the $\mathrm{CH}_{3}$ and $\mathrm{CH}$ bending region at $1400-1250 \mathrm{~cm}^{-1}$, the skeletal stretching (C-O-C) region at $1260-1050 \mathrm{~cm}^{-1}$ and the backbone stretching and $\mathrm{CH}_{3}$ rocking region at $970-850 \mathrm{~cm}^{-1}$. As crystallinity increases the peaks located in these regions become sharper and band splitting occurs in carbonyl and $\mathrm{C}-\mathrm{O}-\mathrm{C}$ stretching regions (Bhatla \& Yao, 2009).

As shown in Figure 3, peaks located in the regions mentioned above increased in intensity when $\mathrm{CaCO}_{3}$ and $\beta$-TCP were added compared to the group of pure PLA. The most important examples are the peak located at $\sim 1750 \mathrm{~cm}^{-1}$ and associated with carbonyl $(\mathrm{C}=\mathrm{O})$ stretching, the peaks related to asymmetric $\mathrm{C}-\mathrm{O}-\mathrm{C}$ stretching at approximately $1180 \mathrm{~cm}^{-1}$ and $1080 \mathrm{~cm}^{-1}$ and the bands at $960 \mathrm{~cm}^{-1}$ and $875 \mathrm{~cm}^{-1}$ arising from C- 
$\mathrm{C}$ backbone stretching and the $\mathrm{CH}_{3}$ rocking mode (Bhatla \& Yao, 2009; Krikorian \& Pochan, 2005). The highest value of crystallinity is expected for the combination of materials where both additives are used. The observed tendency is in accordance with the results obtained from the calorimetric analysis of the printed filaments (Table 2).

\subsection{Water Contact Angle Measurement (WCA)}

WCA measurements of the samples in dry state showed no statically significant difference $(p>0.05)$ of the values between the groups. The results of this test are included in Appendix A, while water contact angle values for samples in pre-wetted state are shown in Table 3. For the later test, it can be concluded that the addition of $\mathrm{CaCO}_{3}$ and $\beta$-TCP effectively reduce the water contact angle of the PLA matrix, as very highly statistically significant difference $(p<0.001)$ between the groups of samples containing additives and the group of PLA samples were obtained. There is not any significant difference $(p>0.05)$ among the composite groups.

\subsection{Mechanical Characterization}

\subsubsection{Compression Test}

Regarding the compression properties, the values of the compressive modulus were $207 \pm 25 \mathrm{MPa}$ for

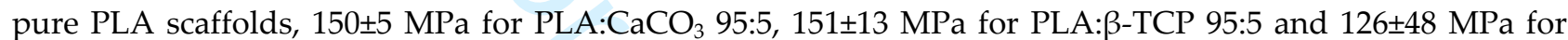
PLA: $\mathrm{CaCO}_{3}: \beta$-TCP 95:2.5:2.5 (Figure 4). These values are in the range of values reported for cancellous bone (20-500 MPa) (Leong, Chua, Sudarmadji, \& Yeong, 2008). Significant differences $(\mathrm{p}<0.05)$ were obtained when comparing PLA:CaCO 3 95:5 and PLA:CaCO $: \beta-\mathrm{TCP}$ 95:2.5:2.5 groups to the group of pure PLA samples, while highly statistically significant differences $(p<0.01)$ were observed for PLA: $\beta$-TCP 95:5. The same conclusion is drawn from the results of the compressive yield strength, as shown in Figure 4 . This parameter decreased from a mean value of 7.7 MPa in the case of pure PLA samples to 5.4 MPa for the groups including one of the additives evaluated in this study, and to 4.9 MPa when both are added. Again, the results are in the range of values for cancellous bone (Leong et al., 2008).

The variation factor for compressive modulus resulted to be $12.3 \%$ for PLA, 3.3\% for PLA:CaCO 3 95:5, 8.3\% for PLA: $\beta$-TCP 95:5 and 37.9\% for PLA:CaCO $: \beta-$ TCP 95:2.5:2.5, which means that the level of reproducibility for the $\mathrm{PLA}: \mathrm{CaCO}_{3}: \beta-\mathrm{TCP} 95: 2.5: 2.5$ group is the worst one. On the other hand, the best results were obtained for the $\mathrm{PLA}: \mathrm{CaCO}_{3}$ 95:5 group, which showed a good level of uniformity for the extruded filament, resulting a similar variation factor to the nominal value of $4 \%$ mentioned in Section 2.3 . The nucleation effect caused by the presence of the additive particles resulted in a good fluidity of this particular composite providing a uniform filament. However, the introduction of both additives in the PLA matrix worsened the variation factor, probably due to a combination of two factors: the poor distribution of the additives in the polymeric matrix due to the high number and size of agglomerates, and the lowest uniformity of the diameter of the PLA: $\mathrm{CaCO}_{3}: \beta-\mathrm{TCP} 95: 2.5: 2.5$ extruded filaments caused by the presence of these agglomerates.

\subsubsection{Bending Test}

According to the results, the value of the flexural modulus and the maximum flexural stress remains unchanged between the groups $(\mathrm{p}>0.05)$ for the non-porous samples obtained by compression moulding, with the first property ranging from 3.1 to $3.3 \mathrm{GPa}$ and being the second one between 19-23 MPa for the four groups of samples evaluated.

Flexural tests performed on the 3D printed scaffolds revealed statistically significant differences between the flexural modulus values of the three groups of samples containing additives and the group of pure PLA samples ( $p<0.05$ for PLA:CaCO $: \beta-$ TCP 95:2.5:2.5 group, and $p<0.01$ for PLA:CaCO ${ }_{3}$ 95:5and PLA: $\beta$-TCP 95:5 groups). The flexural modulus decreased from the mean value of 0.89 GPa of the PLA scaffolds group to $0.47,0.59$ and $0.60 \mathrm{GPa}$ for the PLA:CaCO $\mathrm{CO}_{3}$ 95:5, PLA: $\beta$-TCP 95:5 and PLA:CaCO $: \beta-\mathrm{TCP}$ 95:2.5:2.5 groups, respectively. The flexural modulus of the $\mathrm{PLA}: \mathrm{CaCO}_{3}$ 95:5 group was also significantly lower $(\mathrm{p}<0.05)$ compared to the PLA: $\beta$-TCP 95:5 group. Similar results were obtained regarding the 
maximum flexural stress of the samples, as the values of groups of samples containing additives showed statistically significant differences compared to the group of PLA samples (mean value of $20 \mathrm{MPa}$ ), being the mean value of the $\mathrm{PLA}: \mathrm{CaCO}_{3}$ group significantly lower than the values of every other group (mean values obtained were $11 \mathrm{MPa}$ for PLA:CaCO $395: 5,14 \mathrm{MPa}$ for PLA: $\beta$-TCP 95:5 and $15 \mathrm{MPa}$ for PLA:CaCO $3: \beta-\mathrm{TCP}$ 95:2.5:2.5).

As a conclusion of the bending tests for the two type of samples (porous vs non-porous), it could be stated that the decrease in flexural properties observed for the 3D printed samples is not a consequence of the additive's introduction itself, but is more related to the manufacturing process of the part, which leads to the formation of agglomerates.

\subsection{Metabolic activity of SaOS-2 cells}

The highest mean value of fluorescence in the Alamar Blue test, and therefore the highest metabolic activity of cells attached to the structure after 7 days, was observed for the PLA:CaCO $: \beta-T C P$ 95:2.5:2.5 group, as shown in Figure 5. Very highly statistically significant difference $(p<0.001)$ between this group and the pure PLA scaffolds group was obtained. Also, there are statistically significant differences $(\mathrm{p}<0.05)$ for the group containing both additives compared to the groups of scaffolds containing only $\beta-\mathrm{TCP}$ or $\mathrm{CaCO}_{3}$. According to these results, the use of the additives in the formulation of the samples enhances the metabolic activity of the SaOS-2 cells.

High magnification SEM images from cells located at the 3D printed scaffold's interior are shown in Figure 6, in which we could see that cells have a high degree of spreading after 7 days of culture, showing extended lamellipodia and some filopodia in all tested materials. On the other hand, as shown in Figure 6 (b), cells attached in this case to a PLA:CaCO $395: 5$ scaffold tend to fill and grow within the micropores generated during the manufacturing process. In this way, it was possible to conclude that the cell growth in the composite scaffolds was enhanced not only because of the improved osteoconductivity of the PLA matrix (due to the addition of the $\beta$-TCP particles), but also because of the enhanced microporosity of the structures.

\section{Discussion}

The results obtained proved that the incorporation of $\mathrm{CaCO}_{3}$ and $\beta$-TCP into the PLA matrix of 3D printed scaffolds leads to substantial modification of the characteristics of the final structure. As has been shown in SEM and micro-CT images, the roughness and microporosity of the surface of the 3D printed filaments were significantly increased when additives were used. Both modifications were attributed to the presence of agglomerates of additive particles, as a consequence of the lack of chemical interaction between them and the PLA matrix later confirmed by FTIR analysis. The formation of agglomerates was especially manifest in the case of the PLA:CaCO $: \beta$-TCP 95:2.5:2.5 group, which showed greater dispersion in the results concerning porosity (Table 1 ) and mechanical testing of the scaffolds (Figure 4).

An increase in the crystallinity of the extruded and 3D printed filaments was also observed due to the introduction of additives. This modification can be explained by the nucleation effect caused by the presence of the particles (Alemán-Domínguez, Giusto, et al., 2018; Drummer et al., 2012). Changes induces in the crystallinity of the PLA-based scaffolds alters the degradation rate of the structure (Esposito Corcione et al., 2017), which is a factor of great importance since the bulk degradation of PLA leads to the formation of acidic by-products (Abert et al., 2016; Schiller et al., 2004). Further investigation is needed to evaluate the effect of the addition of $\beta$-TCP (Hutmacher, 2000) and especially $\mathrm{CaCO}_{3}$ into the PLA matrix in order to counteract the $\mathrm{pH}$ decrease.

In contrast to the dry test, in the pre-wetted state of the samples the use of the additives led to a significant reduction of the WCA, i.e., greater surface wettability. This effect has already been observed in polymers that better expose hydroxyl or carboxylic acid groups at the surface only when hydrated (Ratner, 2013). Most studies show that a hydrophilic surface is more conductive to the attachment of cells (Chen et al., 2018). In the present study, a very high statistically significant difference $(p<0.001)$ between the WCA values was obtained when comparing the pure PLA scaffolds group with the composite groups of samples, with mean reduction of a 5.5\% (Table 3). The decrease of the hydrophobicity of the scaffolds surface, coupled with 
the increase of its roughness and microporosity, led to enhanced metabolic activity of cells adhered to the composite scaffolds (Chen et al., 2018; Perez \& Mestres, 2016), as shown in Figure 5. However, the adhesive properties of cells after 7 days of culture appeared to be unaffected by the presence of the additives in the PLA-based scaffolds (Figure 6). A better understanding of this effect could be observed at early culture periods, since in the first 24 hours the surface properties dictate the first cell-material interactions (Ribeiro et al., 2017). In this way, the main differences in relation to cell behaviour were observed in terms of metabolic activity, showing the PLA:CaCO $3: \beta-T C P$ 95:2.5:2.5 group of scaffolds a significantly higher metabolic activity of SaOS-2 cells after 7 days of culture, as compared to the remaining PLA-based constructs.

Regarding the pore size, the distance between filaments was in the range of $400-425 \mu \mathrm{m}$ for all the groups of scaffolds evaluated (Table 1), so according to previous literature the structures obtained fulfil the requirements for bone regeneration (150-500 $\mu \mathrm{m}$ ) (Gómez-Lizárraga et al., 2017). In addition, apparent density values $\left(0.53-0.55 \mathrm{~g} / \mathrm{cm}^{3}\right.$, Table 1$)$ were within the range reported for cancellous bone: $0.14-1.2 \mathrm{~g} / \mathrm{cm}^{3}$ (Deplaine et al., 2014), as well as compressive test results for all the groups of scaffolds tested (Leong et al., 2008). From the bending test results, it can be drawn that the great number of defects in the filaments was the main cause of the decrease of the mechanical properties for the composite scaffolds, but not the additive introduction itself, as no significant differences were observed between the values of the samples obtained by compression moulding. As a conclusion, the agglomerates seem having more influence in their processing than in the behaviour of the composite materials. The improvement of the mixing process prior to the extrusion of the filaments or the reduction of the additive concentration can be alternatives that could lead to the reduction or removal of these agglomerates. In this way, it would be possible to adjust the characteristics of the scaffold to achieve good metabolic activity of cells while maintaining the mechanical properties of the base material. Further research to optimize the scaffold's properties in terms of microporosity and mechanical properties may be conducted, although obtained results for the 3D printed PLA: $\mathrm{CaCO}_{3}: \beta$-TCP 95:2.5:2.5 scaffolds regarding cell behaviour are very promising. This formulation promoted the growth and development of osteoblast-like cells in vitro, confirming the potential application of these structures for bone regeneration.

5. Acknowledgments: Ricardo Donate express his gratitude for the funding through the PhD grant program co-financed by the Canarian Agency for Research, Innovation and Information Society of the Canary Islands Regional Council for Employment, Industry, Commerce and Knowledge and by the European Social Fund (ESF) Canary Islands Integrated Operational Program 2014-2020, Axis 3 Priority Theme 74 (85\%). Grant code: TESIS2017010036.

Also, the authors would like to thank H2020-MSCA-RISE program, as this work is part of developments carried out in BAMOS project, funded from the European Union's Horizon 2020 research and innovation programme under grant agreement № 734156 .

6. Conflict of Interest Statement: The authors declare no conflict of interest. The founding sponsors had no role in the design of the study; in the collection, analyses, or interpretation of data; in the writing of the manuscript, and in the decision to publish the results.

\section{References}

Abert, J., Amella, A., Weigelt, S., \& Fischer, H. (2016). Degradation and swelling issues of poly-(d,1lactide) $/ \beta$-tricalcium phosphate/calcium carbonate composites for bone replacement. Journal of the Mechanical Behavior of Biomedical Materials, 54, 82-92. doi:10.1016/j.jmbbm.2015.09.016

Alemán-Domínguez, M. E., Giusto, E., Ortega, Z., Tamaddon, M., Benítez, A. N., \& Liu, C. (2018). Threedimensional printed polycaprolactone-microcrystalline cellulose scaffolds. Journal of Biomedical Materials Research - Part B Applied Biomaterials. doi:10.1002/jbm.b.34142

Alemán-Domínguez, M. E., Ortega, Z., Benítez, A. N., Vilariño-Feltrer, G., Gómez-Tejedor, J. A., \& VallésLluch, A. (2018). Tunability of polycaprolactone hydrophilicity by carboxymethyl cellulose loading. Journal of Applied Polymer Science, 135(14). doi:10.1002/app.46134

Ara, M., Watanabe, M., \& Imai, Y. (2002). Effect of blending calcium compounds on hydrolytic degradation of poly(DL-lactic acid-co-glycolic acid). Biomaterials, 23(12), 2479-2483. doi:10.1016/S0142-9612(01)00382-9 
Bhatla, A., \& Yao, Y. L. (2009). Effect of laser surface modification on the crystallinity of poly(l-lactic acid). Journal of Manufacturing Science and Engineering, Transactions of the ASME, 131(5), 051004105100411. doi:10.1115/1.3039519

Canadas, R. F., Pina, S., Marques, A. P., Oliveira, J. M., \& Reis, R. L. (2015). Cartilage and Bone Regeneration-How Close Are We to Bedside? In Translating Regenerative Medicine to the Clinic (pp. 89-106).

Chen, S., Guo, Y., Liu, R., Wu, S., Fang, J., Huang, B., . . Chen, Z. (2018). Tuning surface properties of bone biomaterials to manipulate osteoblastic cell adhesion and the signaling pathways for the enhancement of early osseointegration. Colloids and Surfaces B: Biointerfaces, 164, 58-69. doi:10.1016/j.colsurfb.2018.01.022

Chia, H. N., \& Wu, B. M. (2015). Recent advances in 3D printing of biomaterials. Journal of Biological Engineering, 9(1). doi:10.1186/s13036-015-0001-4

Conejero-García, Á., Gimeno, H. R., Sáez, Y. M., Vilariño-Feltrer, G., Ortuño-Lizarán, I., \& Vallés-Lluch, A. (2017). Correlating synthesis parameters with physicochemical properties of poly(glycerol sebacate). European Polymer Journal, 87, 406-419. doi:10.1016/j.eurpolymj.2017.01.001

Deplaine, H., Acosta-Santamaría, V. A., Vidaurre, A., Gómez Ribelles, J. L., Doblaré, M., Ochoa, I., \& Gallego Ferrer, G. (2014). Evolution of the properties of a poly(L-lactic acid) scaffold with double porosity during in vitro degradation in a phosphate-buffered saline solution. Journal of Applied Polymer Science, 131(20). doi:10.1002/app.40956

Domingos, M., Intranuovo, F., Gloria, A., Gristina, R., Ambrosio, L., Bártolo, P. J., \& Favia, P. (2013). Improved osteoblast cell affinity on plasma-modified 3-D extruded PCL scaffolds. Acta Biomaterialia, 9(4), 5997-6005. doi:10.1016/j.actbio.2012.12.031

Drummer, D., Cifuentes-Cuéllar, S., \& Rietzel, D. (2012). Suitability of PLA/TCP for fused deposition modeling. Rapid Prototyping Journal, 18(6), 500-507. doi:10.1108/13552541211272045

Esposito Corcione, C., Gervaso, F., Scalera, F., Montagna, F., Sannino, A., \& Maffezzoli, A. (2017). The feasibility of printing polylactic acid-nanohydroxyapatite composites using a low-cost fused deposition modeling 3D printer. Journal of Applied Polymer Science, 134(13). doi:10.1002/app.44656

Garlotta, D. (2001). A literature review of poly(lactic acid). Journal of Polymers and the Environment, 9(2), 6384.

Gregor, A., Filová, E., Novák, M., Kronek, J., Chlup, H., Buzgo, M., . . Hošek, J. (2017). Designing of PLA scaffolds for bone tissue replacement fabricated by ordinary commercial 3D printer. Journal of Biological Engineering, 11(1). doi:10.1186/s13036-017-0074-3

Gómez-Lizárraga, K. K., Flores-Morales, C., Del Prado-Audelo, M. L., Álvarez-Pérez, M. A., Piña-Barba, M. C., \& Escobedo, C. (2017). Polycaprolactone- and polycaprolactone/ceramic-based 3Dbioplotted porous scaffolds for bone regeneration: A comparative study. Materials Science and Engineering: C, 79(Supplement C), 326-335. doi:https://doi.org/10.1016/j.msec.2017.05.003

Hutmacher, D. W. (2000). Scaffolds in tissue engineering bone and cartilage. Biomaterials, 21(24), 2529-2543. doi:10.1016/S0142-9612(00)00121-6

Kister, G., Cassanas, G., \& Vert, M. (1998). Effects of morphology, conformation and configuration on the IR and Raman spectra of various poly(lactic acid)s. Polymer, 39(2), 267-273. doi:10.1016/S00323861(97)00229-2

Krikorian, V., \& Pochan, D. J. (2005). Crystallization behavior of poly(L-lactic acid) nanocomposites: Nucleation and growth probed by infrared spectroscopy. Macromolecules, 38(15), 6520-6527. doi:10.1021/ma050739z

Leong, K. F., Chua, C. K., Sudarmadji, N., \& Yeong, W. Y. (2008). Engineering functionally graded tissue engineering scaffolds. Journal of the Mechanical Behavior of Biomedical Materials, 1(2), 140-152. doi:https://doi.org/10.1016/j.jmbbm.2007.11.002

Li, Y., Li, D., Lu, B., Gao, D., \& Zhou, J. (2015). Current status of additive manufacturing for tissue engineering scaffold. Rapid Prototyping Journal, 21(6), 747-762. doi:10.1108/RPJ-03-2014-0029

Lou, T., Wang, X., Song, G., Gu, Z., \& Yang, Z. (2014). Fabrication of PLLA/ $\beta$-TCP nanocomposite scaffolds with hierarchical porosity for bone tissue engineering. International Journal of Biological Macromolecules, 69, 464-470. doi:10.1016/j.ijbiomac.2014.06.004

Patrício, T., Domingos, M., Gloria, A., D'Amora, U., Coelho, J. F., \& Bártolo, P. J. (2014). Fabrication and characterisation of PCL and PCL/PLA scaffolds for tissue engineering. Rapid Prototyping Journal, 20(2), 145-156. doi:10.1108/RPJ-04-2012-0037

Perez, R. A., \& Mestres, G. (2016). Role of pore size and morphology in musculo-skeletal tissue regeneration. Materials Science and Engineering C, 61, 922-939. doi:10.1016/j.msec.2015.12.087 


\section{Tables}

Table 1. Bulk and apparent density values of the materials evaluated and porosity and pore size values of the 3D printed scaffolds.

\begin{tabular}{ccccc} 
Material & $\begin{array}{c}\text { Bulk density } \\
(\mathbf{g} / \mathbf{m} 3)\end{array}$ & $\begin{array}{c}\text { Apparent } \\
\text { density }(\mathbf{g} / \mathbf{m} 3)\end{array}$ & Porosity (\%) & Pore size $(\boldsymbol{\mu m})$ \\
\hline PLA & $1.20 \pm 0.03$ & $0.54 \pm 0.03$ & $54.7 \pm 2.2$ & $421.45 \pm 54.53$ \\
PLA:CaCO $95: 5$ & $1.30 \pm 0.04^{3}$ & $0.54 \pm 0.02$ & $58.6 \pm 1.5^{1}$ & $424.61 \pm 51.49$ \\
PLA: $\beta-\mathrm{TCP}^{2} 95: 5$ & $1.34 \pm 0.11^{2}$ & $0.55 \pm 0.01$ & $58.8 \pm 0.8^{2}$ & $396.64 \pm 29.86$ \\
PLA:CaCO $: \beta-\mathrm{TCP}$ & $1.28 \pm 0.07^{1}$ & $0.53 \pm 0.05$ & $58.3 \pm 3.6$ & $410.99 \pm 48.24$ \\
95:2.5:2.5 & & &
\end{tabular}

\footnotetext{
$1 * \mathrm{p}<0.05$ compared to the group of pure PLA samples.

$2{ }^{* *} \mathrm{p}<0.01$ compared to the group of pure PLA samples.

${ }^{3 * * *} \mathrm{p}<0.001$ compared to the group of pure PLA samples.
} 
Table 2. Left limit temperature, melting temperature, enthalpy of fusion and degree of crystallinity values determined from thermogravimetric and calorimetric analysis.

\begin{tabular}{|c|c|c|c|c|c|}
\hline $\begin{array}{l}\text { Type of } \\
\text { sample }\end{array}$ & Material & $\begin{array}{c}\text { Left limit } \\
\text { temperature } \\
\left({ }^{\circ} \mathrm{C}\right)\end{array}$ & $\begin{array}{c}\text { Melting } \\
\text { temperature } \\
\left({ }^{\circ} \mathrm{C}\right)\end{array}$ & $\begin{array}{c}\text { Enthalpy } \\
\text { of fusion } \\
(\mathrm{J} / \mathrm{g})\end{array}$ & $\begin{array}{l}\text { Degree of } \\
\text { crystallinity } \\
(\%)\end{array}$ \\
\hline powder & PLA & 310 & 175 & 46.8 & 50.0 \\
\hline \multirow{4}{*}{$\begin{array}{l}\text { 3D printed } \\
\text { filament }\end{array}$} & PLA & 310 & 173 & 29.4 & 31.4 \\
\hline & PLA: $\mathrm{CaCO}_{3}$ 95:5 & 280 & 173 & 31.4 & 35.3 \\
\hline & PLA: $\beta$-TCP 95:5 & 270 & 174 & 41.3 & 46.4 \\
\hline & $\begin{array}{l}\text { PLA:CaCO }{ }_{3}: \beta- \\
\text { TCP 95:2.5:2.5 }\end{array}$ & 280 & 174 & 44.3 & 49.8 \\
\hline
\end{tabular}

Table 3. Water contact angle values of pre-wetted samples.

\begin{tabular}{|c|c|}
\hline Material & WCA in pre-wetted state $\left(^{\circ}\right)$ \\
\hline PLA & $88.85 \pm 2.24$ \\
\hline PLA: $\mathrm{CaCO}_{3}$ 95:5 & $84.34 \pm 4.17^{1}$ \\
\hline PLA: $\beta$-TCP 95:5 & $83.56 \pm 3.59^{1}$ \\
\hline PLA:CaCO ${ }_{3}: \beta-\mathrm{TCP} 95: 2.5: 2.5$ & $84.05 \pm 3.46^{1}$ \\
\hline
\end{tabular}

\section{Figure legends}

Figure 1. SEM images (scale bar: $1 \mathrm{~mm}$ ) of the 3D printed scaffolds analysed:(a) PLA; (b) PLA:CaCO 3 95:5; (c) PLA: $\beta$-TCP 95:5; (d) PLA:CaCO $: \beta$-TCP 95:2.5:2.5. Also, SEM images with higher magnification (scale bar: $300 \mu \mathrm{m}$ ) are shown for (e)PLA: $\mathrm{CaCO}_{3}$ 95:5 and (f) PLA: $\beta$-TCP 95:5 3D printed scaffolds.

Figure 2. Micro-CT images and 3D reconstructed model of the 3D printed scaffolds analysed. Scale bar: $1.5 \mathrm{~mm}$.

Figure 3. FTIR spectra (region of wavelengths from 3200 to $500 \mathrm{~cm}^{-1}$ ) of PLA extruded filaments and its composites.

Figure 4. Mechanical properties of the $3 \mathrm{D}$ printed scaffolds under compression testing $\left({ }^{*} \mathrm{p}<0.05\right.$ and ${ }^{* *} \mathrm{p}<0.01$ compared to the group of pure PLA samples).

Figure 5. Metabolic activity of SaOS-2 cells on the scaffolds determined by the Alamar Blue assay ( ${ }^{*} \mathrm{p}<0.05$ and *** $\mathrm{p}<0.001)$.

Figure 6. High contrast SEM images (scale bar: $50 \mu \mathrm{m}$ ) of the 3D printed scaffolds after 7 days of cell culture with SaOS-2 cells: (a) PLA; (b) PLA: $\mathrm{CaCO}_{3}$ 95:5; (c) PLA: $\beta$-TCP 95:5; (d) PLA:CaCO $: \beta-\mathrm{TCP}$ 95:2.5:2.5. The red arrow indicates filopodia and the black arrows indicate lamellipodia.

\section{$\underline{\text { Supporting Information }}$}

Figure 7. Mechanical properties under 3 points bending testing of the non-porous samples manufactured by compression moulding.

Figure 8. Mechanical properties of the 3D printed scaffolds under 3 points bending testing $\left({ }^{*} p<0.05\right.$ and ${ }^{* *} p<0.01$ compared to the group of pure PLA samples). 


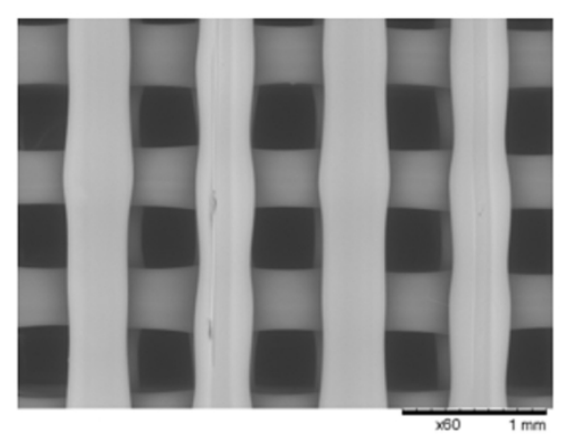

(a)

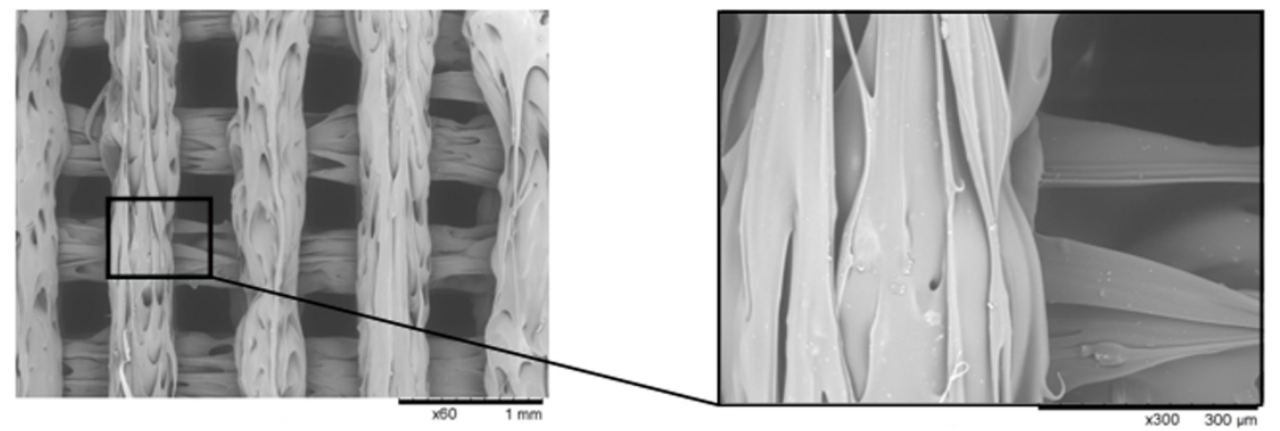

(b)

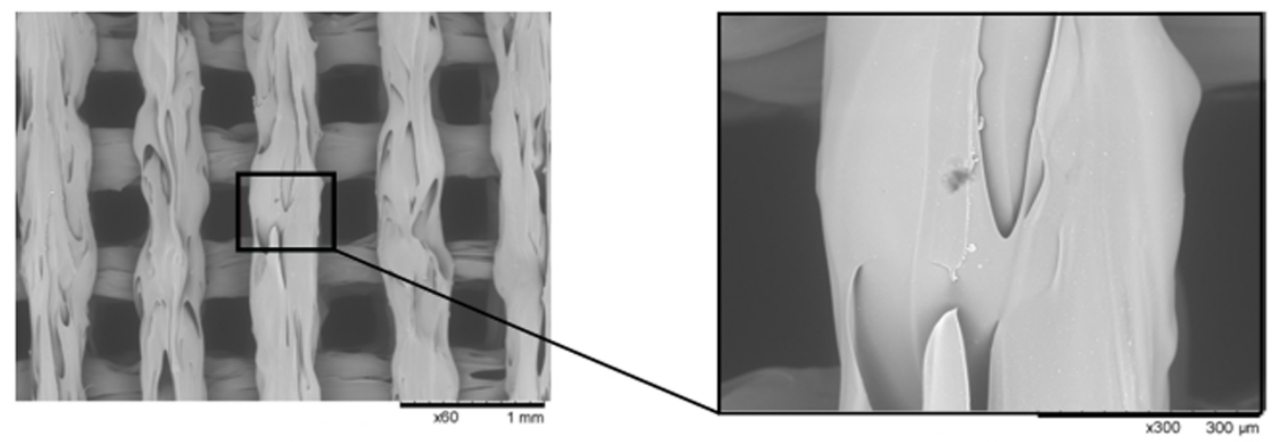

(c)

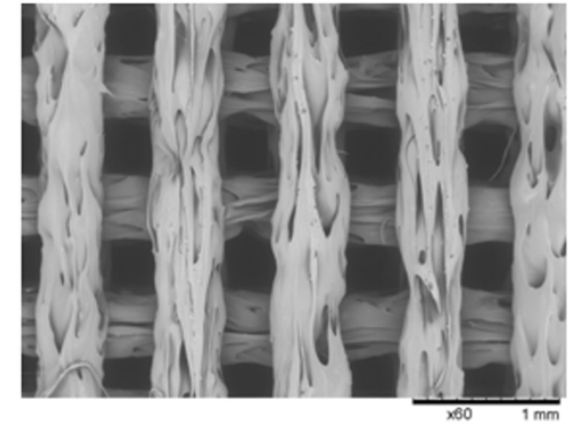

(d)

(e)

(f)

Figure 1. SEM images (scale bar: $1 \mathrm{~mm}$ ) of the 3D printed scaffolds analysed:(a) PLA; (b) PLA:CaCO3 95:5; (c) PLA: $\beta$-TCP 95:5; (d) PLA:CaCO3: $\beta$-TCP 95:2.5:2.5. Also, SEM images with higher magnification (scale bar: $300 \mu \mathrm{m}$ ) are shown for (e) PLA:CaCO3 95:5 and (f) PLA: $\beta-T C P$ 95:5 3D printed scaffolds. $152 \times 181 \mathrm{~mm}(300 \times 300 \mathrm{DPI})$ 


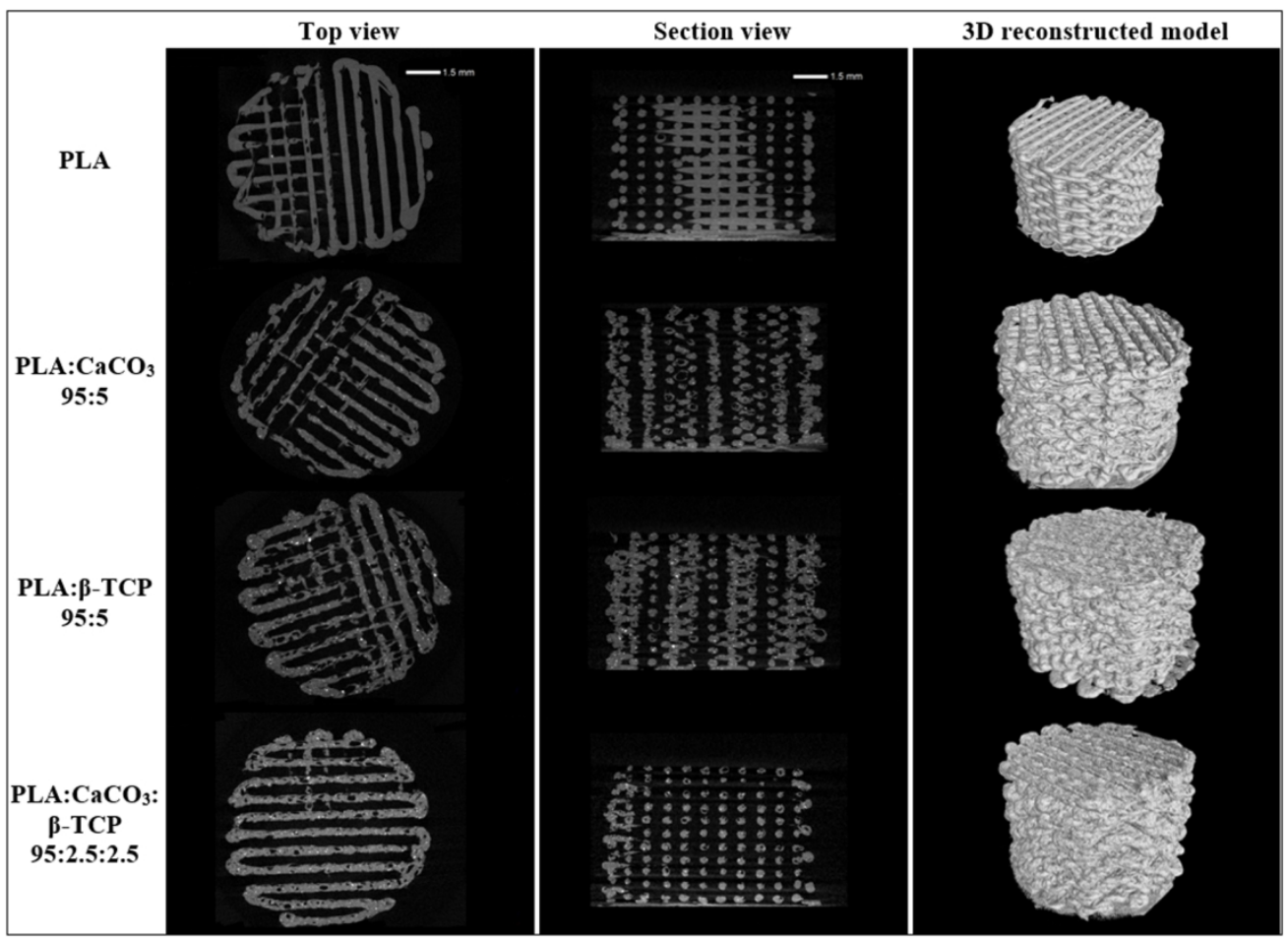

Figure 2. Micro-CT images and 3D reconstructed model of the 3D printed scaffolds analysed. Scale bar: 1.5 $\mathrm{mm}$.

$152 \times 110 \mathrm{~mm}(300 \times 300$ DPI) 
Figure 3. FTIR spectra (region of wavelengths from 3200 to $500 \mathrm{~cm}-1$ ) of PLA extruded filaments and its composites.

$76 \times 46 \mathrm{~mm}(300 \times 300 \mathrm{DPI})$ 


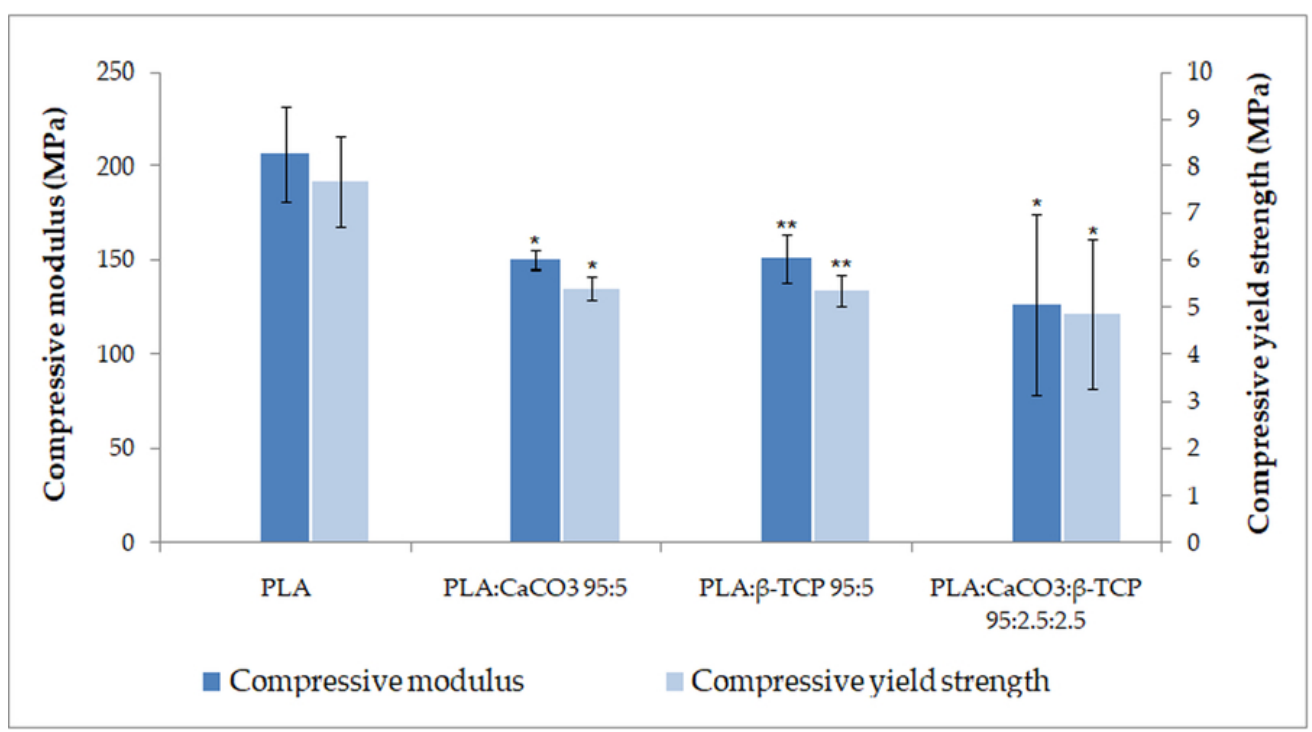

Figure 4. Mechanical properties of the 3D printed scaffolds under compression testing $\left({ }^{*} p<0.05\right.$ and $* * p<0.01$ compared to the group of pure PLA samples).

$76 \times 41 \mathrm{~mm}(300 \times 300 \mathrm{DPI})$ 


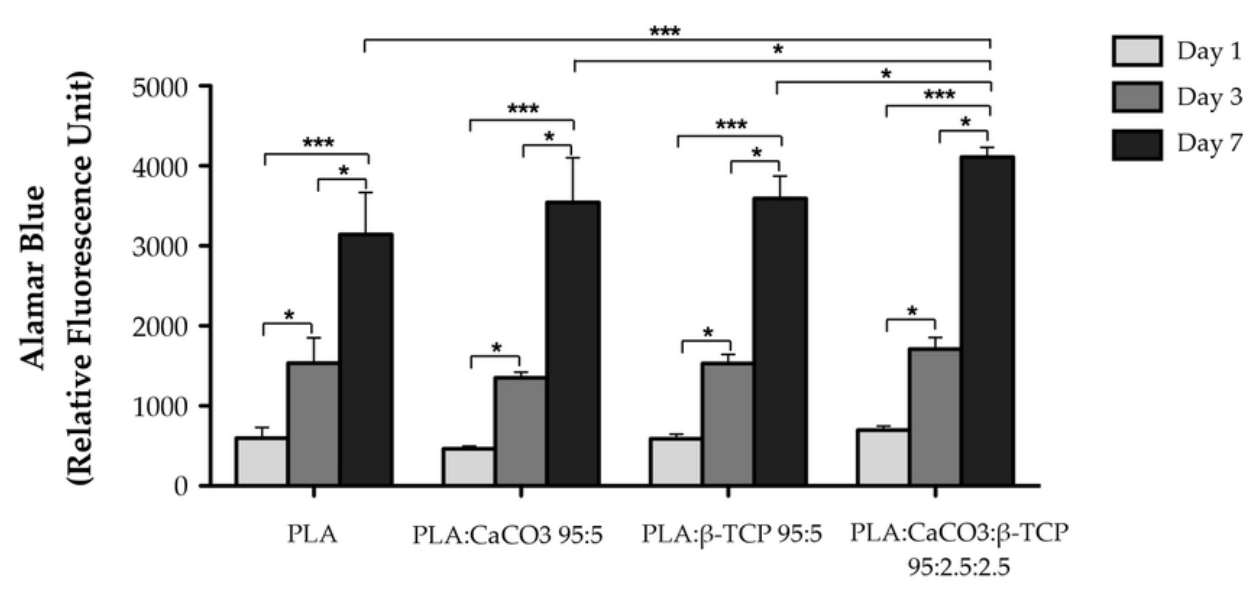

Figure 5. Metabolic activity of SaOs-2 cells on the scaffolds determined by the Alamar Blue assay $(* p<0.05$ and $* * * p<0.001)$.

$76 \times 36 \mathrm{~mm}(300 \times 300$ DPI $)$ 


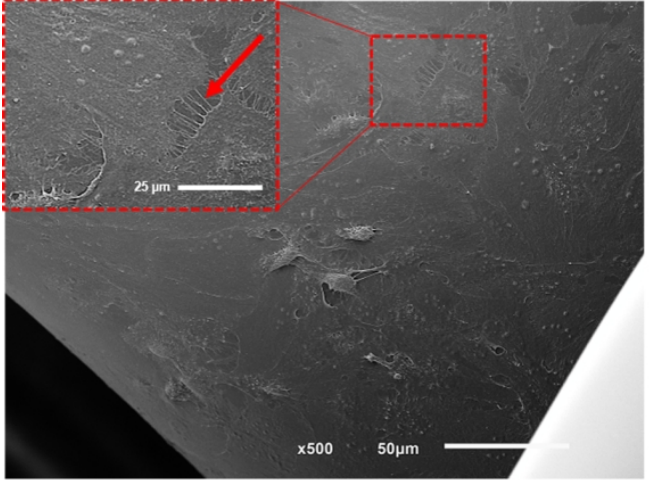

(a)

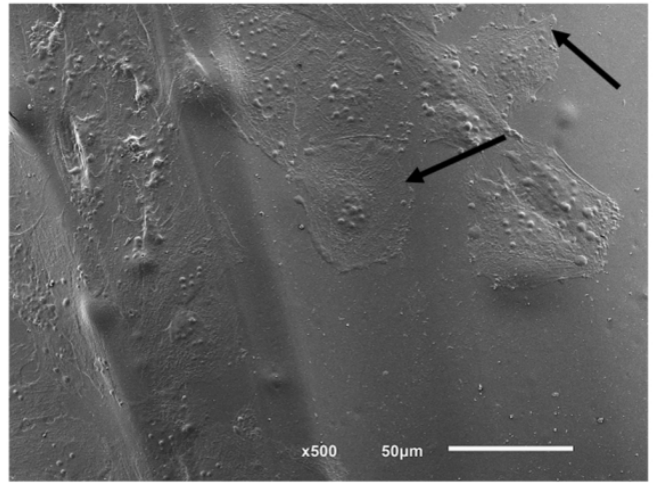

(c)

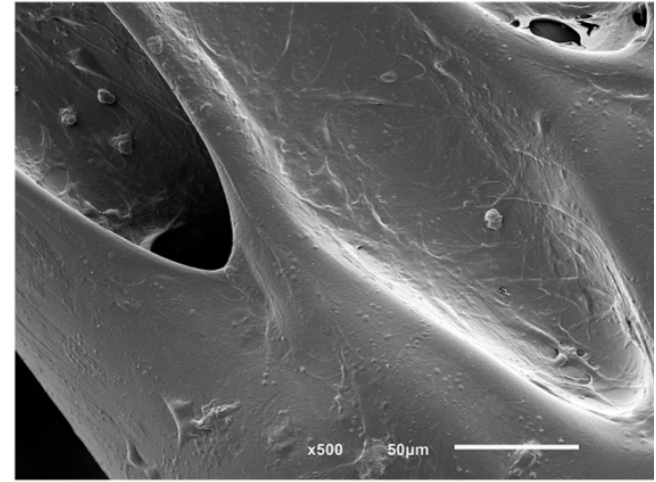

(b)

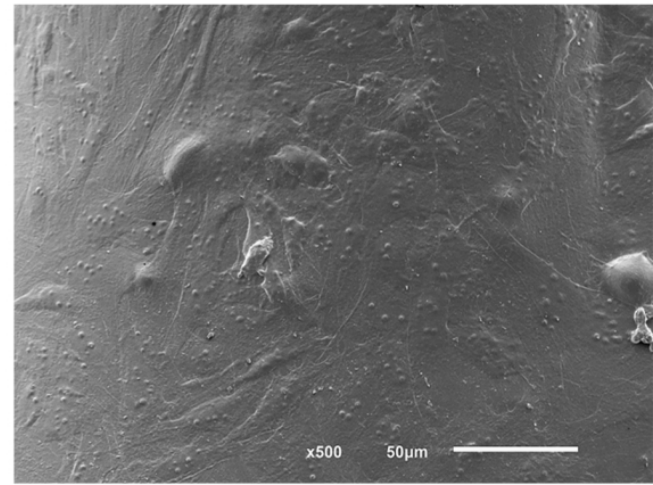

(d)

Figure 6. High contrast SEM images (scale bar: $50 \mu \mathrm{m}$ ) of the 3D printed scaffolds after 7 days of cell culture with SaOS-2 cells: (a) PLA; (b) PLA:CaCO3 95:5; (c) PLA: $\beta$-TCP 95:5; (d) PLA:CaCO3: $\beta$-TCP $95: 2.5: 2.5$. The red arrow indicates filopodia and the black arrows indicate lamellipodia.

$152 \times 132 \mathrm{~mm}(300 \times 300$ DPI $)$ 